\title{
The combined effect of gender and age on post traumatic stress disorder: do men and women show differences in the lifespan distribution of the disorder?
}

\author{
Daniel N Ditlevsen ${ }^{1}$, Ask Elklit ${ }^{2 *}$
}

\begin{abstract}
Background: The aim of the study was to examine the combined effect of gender and age on post traumatic stress disorder (PTSD) in order to describe a possible gender difference in the lifespan distribution of PTSD.

Methods: Data were collected from previous Danish and Nordic studies of PTSD or trauma. The final sample was composed of 6,548 participants, 2,768 (42.3\%) men and 3,780 (57.7\%) women. PTSD was measured based on the Harvard Trauma Questionnaire, part IV (HTQ-IV).

Results: Men and women differed in lifespan distribution of PTSD. The highest prevalence of PTSD was seen in the early 40s for men and in the early 50s for women, while the lowest prevalence for both genders was in the early 70s. Women had an overall twofold higher PTSD prevalence than men. However, at some ages the female to male ratio was nearly 3:1. The highest female to male ratio was found for the 21 to 25 year-olds.

Conclusions: The lifespan gender differences indicate the importance of including reproductive factors and social responsibilities in the understanding of the development of PTSD.
\end{abstract}

\section{Background}

Men and women show differences in the age distribution of post traumatic stress disorder (PTSD) prevalence during their lifespan [1]. Although this is supported by a large and thorough epidemiological study, The National Comorbidity Survey (NCS), the finding is limited by the fact that it only involves participants at the age of 15 to 54 years. This must be regarded as a considerable limitation. The average age of living has been increasing in the modern Western world for more than 200 years [2] and passes far beyond the age of 54 . It therefore seems reasonable to include a broader range of age when estimating the lifespan distribution of PTSD among men and women. The latest updates show that men living in a country within the European Union (EU) have a life expectancy of approximately 76 years, whereas, women have a life expectancy of nearly 82 years [3]. Therefore,

* Correspondence: aelklit@health.sdu.dk

${ }^{2}$ National Centre for Psychotraumatology, University of Southern Denmark, Odense, Denmark individuals now live for an increased number of years compared to that of previous generations; however, as a result individuals also have more years in which they can experience traumatic events or be affected by the potentially negative consequences that follow traumatic experiences.

It therefore becomes important to pay attention to the risk of PTSD in relation to different stages in the lifespan. This will aid in the progression of age adjusted assessment and treatment methods as well as improving the individual coping strategies of PTSD. Men and women show differences in the biological aspects of brain development, thus differences in behavioural development throughout the lifespan could influence the way risk factors or trauma exposures are met [4]. Additionally, gender has been found to be an important biological determinant of vulnerability to psychosocial stress [5]. Therefore, focusing on the lifespan distribution of PTSD makes sense when it accounts for gender 
specific developmental details, and when it combines the effect of gender and age on PTSD.

Gender and age often function as demographic variables in PTSD or trauma research and as such they are both very commonly studied. However, for a great deal of studies neither age nor gender differences are the main area of focus. Numerous gender studies have been conducted with regards to PTSD. The main findings regard the fact that women, although less subjected to potentially traumatic events, develop PTSD more often than men [6-8]. Other studies have reported a twofold increase in PTSD prevalence for women compared to men [9]. Speculations have been made that the increased risk of PTSD among females is due to the higher likelihood of females to experience specific trauma types that appear to be particularly traumatic or PTSD inducing [10]. However, it has been reported that the increased prevalence of PTSD in women remains even when trauma type is controlled for [9]. Indications have been made that different trauma types show variations in the extent of gender differences in PTSD prevalence and as such gender shows variation in its effect on PTSD according to trauma type [11].

Fewer age studies than gender studies are represented in the PTSD literature. Thompson, Norris, and Hanacek [12] examined age differences in the psychological consequences of Hurricane Hugo and found that younger people exhibited the most distress in the absence of a disaster, whereas, middle-aged people exhibited most distress in the presence of a disaster. It is obvious to think that increased levels of distress are coherent with an increased risk of PTSD. Norris et al. [13] examined the effects of age on PTSD in a cultural context, and compared the effects of age after similar disasters in three different parts of the world. The findings showed no consistent effect of age on PTSD. Therefore, it was concluded that PTSD depended upon the social, economic, cultural, and historical context of the disasterstricken setting more than it depended on age. They found inconsistent results among respondents from the USA, Mexico, and Poland, where the most distressed were the middle aged, the young, and the old, respectively. Thus, the age differences in PTSD prevalence tend to show some cultural variance.

In one of the most comprehensive epidemiological studies of PTSD conducted to date, the NCS [1], results concluded both gender and age differences in PTSD. The results pertaining to gender differences concluded that women were approximately twice as likely as men to develop PTSD during their lifetime. This finding has since become well established with subsequent studies reaching similar conclusions [6,9]. Interestingly, Kessler and his colleagues concluded no age differences in lifetime rates of PTSD for males across different age groups. However, for women it was suggested that when age increases PTSD rates tend to decrease [1]. The results showed that combining gender and age leads to further information about the prevalence of PTSD. Among the male participants the prevalence of PTSD was highest from their mid 40 s to their mid 50s, whereas, the female participants showed the highest prevalence of PTSD from their mid 20s to their mid 30s. The results regarding PTSD prevalence are shown in Table 1.

From the findings of previous research it appears that men and women have different developmental distributions of PTSD during their lifetime. Although the findings by Kessler and colleagues [1] are interesting in this regard, they are still, as mentioned above, limited by the fact that the study only included data on participants between 15 and 54 years of age. Therefore, the study did not include the age extremities of childhood or late life. The relevance of including childhood in the developmental distribution of PTSD during lifetime may seem superfluous or controversial for several reasons. However, the inclusion of childhood would essentially comprise the basis of comparison among the age groups because of obvious biological and psychological differences between children and adults, which may be regarded as important for the perception of the trauma and coping strategies. The inclusion of the age extremities beyond the age of 54 seems otherwise relevant especially with an increasing tendency for the average person to reach old age.

Another comprehensive epidemiological study based on data from the Australian National Survey of Mental Health [14] included participants beyond the age of 54 . This study found incoherence for PTSD prevalence rates and exposure to trauma across the lifespan. Results showed that PTSD prevalence reduced with age for both men and women, whereas, a nearly symmetrically inverted $U$-shaped curvilinear pattern of lifetime

Table 1 PTSD prevalence estimates from nationally representative studies

\begin{tabular}{|c|c|c|c|c|}
\hline & \multicolumn{2}{|c|}{ Kessler et al. [1] } & \multicolumn{2}{|c|}{ Creamer and Parslow [14] } \\
\hline & Male & Female & Male & Female \\
\hline \multicolumn{5}{|c|}{ Age, years: } \\
\hline 15 to 24 & 2.8 & 10.3 & $3.8^{*}$ & $5.9^{*}$ \\
\hline 25 to 34 & 5.6 & 11.2 & 2.5 & 4.6 \\
\hline 35 to 44 & 5.0 & 10.6 & 2.0 & 3.1 \\
\hline 45 to 54 & 7.6 & 8.9 & 2.2 & 3.7 \\
\hline 55 to 64 & NA & NA & 2.0 & 1.5 \\
\hline $65+$ & NA & NA & 0.4 & 0.0 \\
\hline Total & 5.0 & 10.4 & 2.0 & 3.2 \\
\hline
\end{tabular}

*The result is only based on data from the age of 18 to 24 years. NA = not available as this age group was not included in the study; PTSD = post traumatic stress disorder. 
exposure to trauma across the lifespan was found for women and a linear increase in lifetime exposure to trauma was found for men. Both male and female participants above the age of 65 reported negligible rates of PTSD. Women showed a higher level of PTSD prevalence in young age and in adulthood compared to men. This effect was seen until the mid 50 s where men started to show a higher PTSD prevalence than women. The results of PTSD prevalence among men and women from the study are shown in Table 1 . The findings suggested that the highest rates of PTSD prevalence among both men and women are found between the age of 18 and 24 years and the lowest among older people [14]. However, it is important to note that the study only included participants above the age of 18 . Some evidence points to the fact that potentially traumatic events as well as the risk of developing PTSD are as much a part of adolescence as it is part of adulthood [15]. Interestingly, the tendency of PTSD prevalence rates declining from young age to old age follows the clinical picture found for PTSD in Danish normative data for the Millon Clinical Multiaxial Inventory III (MCMI-III) [16]. Here, a linear decrease in PTSD prevalence rates according to age was found. This study also concluded a significantly higher score for women compared to men with regards to PTSD.

The finding of low PTSD prevalence in older people is consistent with some studies [17] but inconsistent with others [18,19]. Maercker et al. [18] found a substantially higher prevalence of PTSD among participants in the age range of 60 to 93 years compared to the participants below 60 years of age. Thus, the results showed a linear increase in the prevalence of PTSD. However, the increase in prevalence of PTSD among older people could to a large extent be explained by World War II trauma, making the results interesting but also less representative and comparable to populations from nonWorld War II countries or countries less involved in the war. Elklit and O'Connor [20] examined the occurrence of PTSD in a Danish population sample of older people who had been bereaved. They found that $27 \%$ met all four core criteria for PTSD 1 month after losing their spouse; this number was reduced to $17 \% 6$ months after the loss. Findings showed that an additional $16 \%$ met a subclinical level of PTSD (missing one criterion) 1 month after the loss. This number had increased to $28 \%$ after 6 months. The study did not include genderrelated findings. However, elsewhere suggestions have been made that increased age is a bigger risk factor of PTSD for men than it is for women [21], and that younger age significantly predicts PTSD in women but not in men [22]. This is concordant with findings indicating that the mean onset age of PTSD is higher among men than among women [23].
Although the existence of a combined effect of gender and age on PTSD rates is implied by various studies, the results are ambiguous and the differences in lifespan distribution of PTSD among men and women remain unclear. It is the aim of the present study to expand previous research by including a larger number of participants 55 or older and examining the differences in lifespan distribution among men and women, respectively, along with the possible combined effect of gender and age on PTSD prevalence in order to clarify the extent and consequences of such an effect. Knowledge of the lifespan distribution of PTSD could contribute to the aetiology or phenomenology of PTSD. Furthermore, knowledge of such could be beneficial in relation to the assessment or treatment of PTSD. With the previous findings in the PTSD literature in mind, we find it relevant to examine the following hypotheses concerning the lifespan distribution of PTSD prevalence: (a) the lifespan distribution of PTSD will be different for men and women; (b) women will at all ages show a higher prevalence of PTSD than men; (c) men will show their highest level of PTSD prevalence later in life compared to women.

\section{Methods}

\section{Procedure and participants}

The criteria for including studies were: (a) the study included both male and female participants; (b) the Harvard Trauma Questionnaire (HTQ) was used for assessment in the study and thus could be a measure of comparison for the included studies. All studies that did not fulfil the abovementioned criteria were excluded from the study analysis. In addition, the participants (a) should have notified their gender; (b) be between 13 and 80 years of age; and (c) have given full information on the HTQ. Participants who did not fulfil these criteria were excluded.

Two sets of data were made for analysis. A total sample, which included participants from all the studies both epidemiological population samples and convenience samples of different trauma events, and a trauma sample, including only the participants from the convenience samples of different traumatic events within five trauma types; disasters and accidents, loss, malignant disease, non-malignant disease, and violence.

The data for the total sample consequently consisted of data from 25 different studies of trauma and PTSD that were conducted between 1996 and 2008 (Table 2). The final sample was composed of 6,548 participants, 2,768 (42.3\%) men and 3,780 (57.7\%) women. The age distribution of the participants ranged from 13 to 80 years of age. Of the included studies, 20 were carried out in Denmark, 4 in Iceland, and 1 in the Faroe Islands. 
Table 2 Convenience and epidemiological samples included in the present study

\begin{tabular}{|c|c|c|c|}
\hline Category & Male & Female & Total \\
\hline \multicolumn{4}{|l|}{ Disaster and accident: } \\
\hline Earthquake victims & 33 & 40 & 73 \\
\hline Explosion affected residents & 226 & 235 & 461 \\
\hline Rescue personnel dealing with explosion & 397 & 28 & 425 \\
\hline Whiplash victims & 296 & 1,131 & 1,427 \\
\hline \multicolumn{4}{|l|}{ Violence: } \\
\hline Assault victims & 138 & 50 & 188 \\
\hline Knife homicide at a Danish gymnasium & 107 & 172 & 279 \\
\hline Robbery victims & 20 & 34 & 54 \\
\hline \multicolumn{4}{|l|}{ Malignant or severe disease: } \\
\hline Families with chronically ill children & 32 & 53 & 85 \\
\hline Parents of chronically ill children & 147 & 312 & 459 \\
\hline \multicolumn{4}{|l|}{ Non-malignant disease: } \\
\hline $\begin{array}{l}\text { Adolescent and young adults surviving } \\
\text { childhood cancer }\end{array}$ & 19 & 25 & 44 \\
\hline Cleft surgery patients & 18 & 4 & 22 \\
\hline Overweight persons & 15 & 141 & 156 \\
\hline Paraplegics & 147 & 69 & 216 \\
\hline Parents of prematurely born children & 18 & 40 & 58 \\
\hline Stutterers & 22 & 6 & 28 \\
\hline \multicolumn{4}{|l|}{ Loss: } \\
\hline $\begin{array}{l}\text { Older people who have been bereaved (pilot } \\
\text { study) }\end{array}$ & 20 & 38 & 58 \\
\hline $\begin{array}{l}\text { Older people who have been bereaved (new } \\
\text { study) }\end{array}$ & 248 & 314 & 562 \\
\hline Parents who have lost an infant (hospital) & 44 & 55 & 99 \\
\hline $\begin{array}{l}\text { Parents who have lost an infant (parent } \\
\text { association) }\end{array}$ & 264 & 353 & 617 \\
\hline \multicolumn{4}{|l|}{ Youth samples: } \\
\hline Danish national youth probability sample & 145 & 132 & 277 \\
\hline Faroese youth population total sample & 217 & 242 & 459 \\
\hline Icelandic national youth probability sample & 73 & 80 & 153 \\
\hline \multicolumn{4}{|l|}{ Students: } \\
\hline Social and Health Care College Students & 37 & 83 & 120 \\
\hline \multicolumn{4}{|l|}{ Others: } \\
\hline $\begin{array}{l}\text { Control group from the study of parents who } \\
\text { have lost an infant }\end{array}$ & 21 & 25 & 46 \\
\hline Trauma clients in treatment & 64 & 118 & 182 \\
\hline Total & 2,768 & 3,780 & 6,548 \\
\hline
\end{tabular}

The data for the trauma sample consequently consisted of data from 17 different convenience samples of trauma and PTSD. The final sample consisted of 4,998 participants, 2,039 (40.8\%) men, and 2,959 (59.2\%) women. The age distribution of the participants ranged from 13 to 80 years of age. The frequency of the 13 to 15 year olds was low in the trauma sample.

For both the total sample and the trauma sample the participants were divided into 14 different age groups with a 5-year span in age for analysis except the age group of 13 to 15 year olds, which only had a 3-year span in age. Three of the included studies were undertaken in Iceland, and the others were completed in Denmark.

All studies included met the ethical guidelines for Nordic psychologists. Studies within the hospital sector were approved by a regional Helsinki committee.

\section{Measures}

The questionnaires used for measurement varied between the individual studies. All questionnaires in the selected studies requested data about gender and age of the participants. The HTQ [24] was used in a Danish, Icelandic or Faroese edition. The HTQ estimates PTSD diagnosis according to the Diagnostic and Statistical Manual of Mental Disorders, fourth edition (DSM-IV) [25] and at the same time it measures the severity of PTSD symptoms. The HTQ-IV hereby permits a dichotomous assessment of PTSD. The HTQ originally contained 30 items based on the 3 subscales of PTSD concerning a potentially distressing event. The answers are scored on a four-point Likert scale (1, 'not at all'; 2 , 'a little'; 3 , 'quite a bit'; 4, 'all the time'). Only scale items above or equal to 3 on the HTQ were considered for a PTSD diagnosis. In all the included studies an item was added or regarding feelings of guilt for something done or omitted. Some studies also divided item 16 (sudden emotional or physical reactions when reminded of the incident) into two questions. However, this additional item was not included in the HTQ total scores used for analysis in the present study, giving a total of 31 items with a possible total HTQ score in the range of 0 to 124 . A total of 16 items were related to the 3 subscales of PTSD in DSM-IV: avoidance (7 items), re-experiencing (4 items), and arousal (5 items). Mollica et al. [24] have reported good internal consistency, test-retest reliability, and concurrent validity. The HTQ has been used extensively in the Nordic countries [26].

\section{Statistical analyses}

Data were analysed using SPSS V.17.0 (SPSS, Chicago, IL, USA). Statistical tests included descriptive analyses performed on the data using mean scores, standard deviation (SD), and percentages. One-way analyses of variance (ANOVAs) with descriptive statistics were performed to compare the independent variables of gender and age, and the continuous dependent psychometric variable of the HTQ total score. Both the HTQ mean score as well as a categorical PTSD score were ranked by age groups. Both the HTQ mean scores as well as the categorical PTSD scores can be seen as a way to estimate the vulnerability to PTSD. The dimensional and categorical results of PTSD were both ranked by age groups in order to find the estimated distribution of PTSD prevalence according to age. 


\section{Results}

\section{Total sample}

Ages ranged from 13 to 80 years. For men the mean age was 37.5 years $(S D=17.9)$ and for women it was 38.1 years $(S D=16.5)$. Of the participants, $21.3 \%$ ( $n=1,395 ; 13 \%$ of the men and $27.4 \%$ of the women) suffered from PTSD. Women had higher total HTQ scores than men at all ages $\left(F_{(1,6,547)}=532.5\right.$; $P<0.000)$. The total HTQ score was $48.57(\mathrm{SD}=17.26)$ for men and $59.00(\mathrm{SD}=18.63)$ for women. Women showed higher scores for the subscales re-experience, avoidance, and arousal at all ages. Except for the age 71 to 75 years, which showed a higher score for men (mean $=10.86, \mathrm{SD}=3.93)$ compared to women (mean $=10.63, \mathrm{SD}=3.53$ ) for the subscale avoidance. The mean score of re-experience was $6.89(\mathrm{SD}=2.66)$ for men and $8.36(\mathrm{SD}=2.90)$ for women. The mean score of avoidance was $10.98(\mathrm{SD}=4.54)$ and 12.98 (5.01) for men and women, respectively. For arousal men showed a mean score of $9.16(\mathrm{SD}=3.92)$ and women a mean score of 11.91 ( $\mathrm{SD}=4.20)$. All subscale gender differences were significant (all F values $>275$; all $P$ values $<0.000$ ). The mean and SD values for the 14 age groups can be seen in Table 3 . The HTQ mean scores for these 14 groups are also illustrated in Figure 1 for men and women, respectively.

The highest prevalence of PTSD for men (18.2\%) was found in the age group of 41 to 45 years while women showed their highest prevalence of PTSD (42.8\%) in the age group of 51 to 55 years. The lowest prevalence of PTSD was found at the age of 71 to 75 years for both men $(6.8 \%)$ and women $(10.3 \%)$. The total HTQ score was highest at the age of 41 to 45 years for men (mean =
$51.71, \mathrm{SD}=20.84)$ and at the age of 51 to 55 years for women $($ mean $=64.60, \mathrm{SD}=17.17)$. The lowest level of total HTQ score was found at the age of 66 to 70 years for men $($ mean $=43.51, S D=10.22)$ and at the age of 71 to 75 years for women $($ mean $=46.91, \mathrm{SD}=11.25)$.

A two-way between-groups analysis of variance was conducted to explore the impact of gender and age (based on 5-year spans) on levels of PTSD, as measured by the HTQ. There was a statistically significant main effect for age $\left(F_{(13,6,535)}=12.1 ; P<0.000\right)$; however, the effect size was small (partial eta $^{2}=0.024$ ). The main effects for gender $\left(F_{(1,6,547)}=333.2 ; P<0.000\right)$ and the interaction effect for gender $\times$ age $\left(F_{(13,6,535)}=3.1 ; P<\right.$ $0.000)$ were also significant; the effect sizes were, however, also small (partial eta ${ }^{2}=0.049$ and 0.006, respectively). Post hoc comparisons using the Tukey B test revealed that the male 41 to 45 years age sample and the female 51 to 55 years age sample were significantly higher in HTQ total scores than the 66 to 70 and the 71 to 75 samples for both genders. The other age groups did not differ significantly from each other.

\section{Trauma sample}

Ages ranged from 13 to 80 years. The mean age for men was 40.7 years $(S D=15.1)$ and for women it was 40.6 years $(\mathrm{SD}=14.1)$. Of the participants, $21.9 \%(\mathrm{n}=1,091$; $13.8 \%$ of the men and $27.5 \%$ of the women) suffered from PTSD. At all ages, women showed higher levels of total HTQ score. The total HTQ score for men was 48.71 ( $\mathrm{SD}=17.57)$. For women, the total HTQ score was $59.29(\mathrm{SD}=18.30)$. The mean and standard deviation values for the trauma sample can be seen in Table 4 and

Table 3 Comparison of the different age groups by gender in the total sample

\begin{tabular}{|c|c|c|c|c|c|c|c|c|c|c|}
\hline \multirow[t]{2}{*}{ Age, years } & \multicolumn{4}{|l|}{ Men } & \multicolumn{4}{|c|}{ Women } & \multicolumn{2}{|l|}{ Total } \\
\hline & $\bar{N}$ & PTSD, n & PTSD, \% & HTQ total (SD) & $\mathrm{N}$ & PTSD, n & PTSD, \% & HTQ total (SD) & PTSD, \% & HTQ total (SD) \\
\hline 13 to 15 & 441 & 50 & 11.3 & $49.85(17.56)$ & 463 & 144 & 31.1 & 61.15 (20.59) & 21.5 & $55.64(19.98)$ \\
\hline 16 to 20 & 217 & 16 & 7.4 & $45.93(13.56)$ & 237 & 50 & 21.1 & $57.11(16.47)$ & 14.5 & $51.76(16.13)$ \\
\hline 21 to 25 & 162 & 19 & 11.7 & $46.60(17.32)$ & 178 & 60 & 33.7 & $60.69(20.11)$ & 23.2 & $53.98(20.08)$ \\
\hline 26 to 30 & 230 & 34 & 14.8 & $48.98(16.50)$ & 378 & 99 & 26.2 & $60.01(18.20)$ & 21.9 & $55.84(18.24)$ \\
\hline 31 to 35 & 305 & 44 & 14.4 & $49.86(18.31)$ & 500 & 133 & 26.6 & 59.00 (19.98) & 22.0 & $55.53(19.85)$ \\
\hline 36 to 40 & 317 & 46 & 14.5 & 49.38 (19.06) & 507 & 123 & 24.3 & $58.87(18.20)$ & 20.5 & $55.22(19.09)$ \\
\hline 41 to 45 & 247 & 45 & 18.2 & $51.71(20.84)$ & 413 & 119 & 28.8 & 60.20 (19.10) & 24.8 & $57.02(20.18)$ \\
\hline 46 to 50 & 214 & 34 & 15.9 & 49.64 (19.63) & 289 & 73 & 25.3 & 60.45 (17.70) & 21.3 & 55.85 (19.28) \\
\hline 51 to 55 & 159 & 25 & 15.7 & $49.84(16.91)$ & 257 & 110 & 42.8 & $64.60(17.17)$ & 32.5 & $58.96(18.50)$ \\
\hline 56 to 60 & 117 & 16 & 13.7 & 46.09 (14.76) & 146 & 57 & 39.0 & $61.56(17.60)$ & 27.8 & 54.68 (18.09) \\
\hline 61 to 65 & 72 & 7 & 9.7 & $46.24(14.27)$ & 80 & 22 & 27.5 & $54.54(16.95)$ & 19.1 & $50.61(16.22)$ \\
\hline 66 to 70 & 127 & 9 & 7.1 & $43.51(10.22)$ & 153 & 21 & 13.7 & 48.12 (13.07) & 10.7 & $46.03(12.07)$ \\
\hline 71 to 75 & 103 & 7 & 6.8 & $44.91(11.20)$ & 116 & 12 & 10.3 & $46.91(11.25)$ & 8.7 & $45.97(11.25)$ \\
\hline 76 to 80 & 57 & 7 & 12.8 & 45.95 (12.59) & 63 & 13 & 20.6 & 51.38 (14.37) & 16.7 & $48.80(13.77)$ \\
\hline All ages & 2,768 & 359 & 13.0 & 48.57 (17.26) & 3,780 & 1,036 & 27.4 & $59.00(18.63)$ & 21.3 & 54.59 (18.78) \\
\hline
\end{tabular}

Mean (SD) values for the 14 age groups are shown for men and women.

HTQ = Harvard Trauma Questionnaire part IV; PTSD = post traumatic stress disorder. 


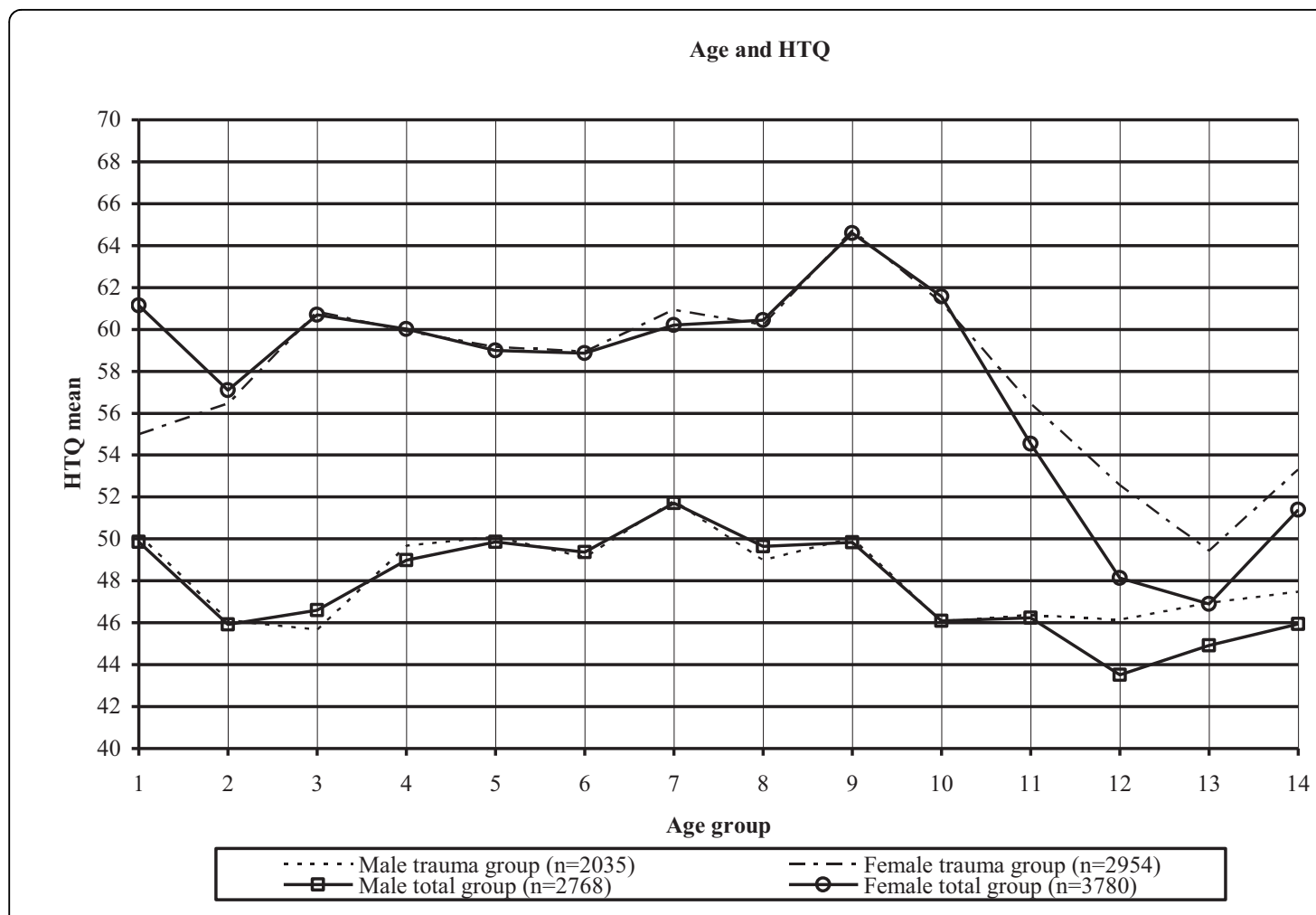

Note: HTQ (= Harvard Trauma Questionnaire) mean scores by gender and age are shown for the total sample and the trauma sample, respectively.

Age group 1: 11-15 years of age Age group 5: 31-35 years of age Age group 9: 51-55 years of age Age group 13: 71-75 years of age
Age group 2: 16-20 years of age Age group 6: 36-40 years of age Age group 10: $56-60$ years of age Age group 14: 76-80 years of age
Age group 3: 21-25 years of age Age group 7: 41-45 years of age

Age group 11: 61-65 years of age
Age group 4: 26-30 years of age Age group 8: 46-50 years of age Age group 12: 66-70 years of age

Figure 1 Lifespan distribution of post traumatic stress disorder (PTSD) based on Harvard Trauma Questionnaire part IV (HTQ) mean scores.

the total HTQ score for the 14 age groups are illustrated in Figure 1 for men and women, respectively.

The prevalence of PTSD was highest among men $(18.3 \%)$ at the age of 41 to 45 years. For women the highest prevalence (43.0\%) was found for the age 51 to 55 years. The lowest PTSD prevalence for men (7.7\%) was seen at the age of 16 to 20 years and for women (13.9\%) it was seen at the age of 71 to 75 years. The mean total HTQ score was highest at the age of 41 to 45 years for men (51.81; $\mathrm{SD}=21.17)$ and at the age of 51 to 55 years for women (64.73; $\mathrm{SD}=17.32)$. It was found to be lowest at the age of 21 to 25 and 71 to 75 years for men (45.66; $\mathrm{SD}=17.46)$ and women (49.43; $\mathrm{SD}=11.75)$, respectively. The PTSD prevalence in both the total sample and the trauma sample was twofold higher among women than among men. The highest difference in PTSD prevalence between men and women in the total sample was found for the 21 to 25 -year-olds who showed a nearly threefold increase in prevalence among women compared to men. The smallest gender difference in PTSD prevalence was found for the 71 to 75 -year-olds who showed a 1.5-fold higher prevalence among women than among men. The trauma sample showed similar results but here the highest difference in PTSD prevalence between men and women was found for the 61 to 65 years sample who showed a more than threefold larger prevalence among women compared to men. For the 21 to 25 years sample a threefold difference was also seen. The smallest difference in PTSD prevalence between men and women was found for the 71 to 75 years sample just like it was seen in the total sample. In the trauma group, the 71 to 75 years sample also showed a ratio of 1 to 1.5 between men and women.

\section{Ranking of age groups from the total sample}

The results showed some differences in the rank of age groups due to a dimensionally (HTQ) or a categorically (PTSD\%) estimated PTSD prevalence. The rankings of the age groups from the total sample can be seen in Table 5. The highest rank for women by both PTSD percentages and HTQ scores was found for women at the age of 51 to 55 years. For men the highest rank for 
Table 4 Comparison of the different age groups by gender in the trauma sample

\begin{tabular}{|c|c|c|c|c|c|c|c|c|c|c|}
\hline \multirow[t]{2}{*}{ Age, years } & \multicolumn{4}{|l|}{ Men } & \multicolumn{4}{|c|}{ Women } & \multicolumn{2}{|l|}{ Total } \\
\hline & $\mathrm{N}$ & PTSD, n & PTSD, \% & HTQ total (SD) & $\mathrm{N}$ & PTSD, n & PTSD, \% & HTQ total (SD) & PTSD, \% & HTQ total (SD) \\
\hline 13 to 15 & 5 & 1 & 20.0 & $50.20(9.26)$ & 9 & 3 & 33.3 & $55.00(15.35)$ & 28.6 & $53.29(13.31)$ \\
\hline 16 to 20 & 195 & 15 & 7.7 & $46.11(13.63)$ & 219 & 43 & 19.6 & $56.47(16.28)$ & 14.0 & $51.59(15.94)$ \\
\hline 21 to 25 & 137 & 15 & 10.9 & $45.66(17.46)$ & 136 & 45 & 33.1 & $60.84(20.53)$ & 22.0 & $53.22(24.48)$ \\
\hline 26 to 30 & 202 & 32 & 15.8 & $49.67(17.13)$ & 335 & 86 & 25.7 & $59.91(17.83)$ & 22.0 & $56.06(18.25)$ \\
\hline 31 to 35 & 275 & 40 & 14.5 & $50.09(18.68)$ & 468 & 123 & 26.3 & $59.16(19.87)$ & 21.9 & $55.80(19.92)$ \\
\hline 36 to 40 & 291 & 39 & 13.4 & $49.10(18.94)$ & 472 & 115 & 24.4 & $58.93(18.36)$ & 20.2 & $55.18(19.18)$ \\
\hline 41 to 45 & 235 & 43 & 18.3 & $51.81(21.17)$ & 385 & 113 & 29.4 & $60.39(19.29)$ & 25.2 & $57.14(20.44)$ \\
\hline 46 to 50 & 206 & 30 & 14.6 & $48.98(19.31)$ & 278 & 65 & 23.4 & $60.21(17.81)$ & 19.6 & $55.43(19.26)$ \\
\hline 51 to 55 & 153 & 25 & 16.3 & $50.02(17.17)$ & 242 & 104 & 43.0 & $64.73(17.32)$ & 32.7 & $59.03(18.67)$ \\
\hline 56 to 60 & 116 & 16 & 13.8 & $46.08(14.83)$ & 137 & 54 & 39.4 & $61.28(17.75)$ & 27.7 & $54.31(18.11)$ \\
\hline 61 to 65 & 58 & 6 & 10.3 & $46.36(13.40)$ & 55 & 18 & 32.7 & $56.45(16.52)$ & 21.2 & $51.27(15.77)$ \\
\hline 66 to 70 & 58 & 6 & 10.3 & $46.14(10.52)$ & 93 & 19 & 20.4 & $52.57(13.92)$ & 16.6 & $50.10(13.07)$ \\
\hline 71 to 75 & 63 & 6 & 9.5 & $46.94(11.92)$ & 72 & 10 & 13.9 & $49.43(11.75)$ & 11.9 & $48.27(11.85)$ \\
\hline 76 to 80 & 41 & 6 & 14.6 & $47.46(13.38)$ & 53 & 13 & 24.5 & $53.30(14.34)$ & 20.2 & $50.76(14.16)$ \\
\hline All ages & 2,035 & 280 & 13.8 & $48.71(17.57)$ & 2,954 & 811 & 27.5 & $59.29(18.30)$ & 21.9 & $54.97(18.74)$ \\
\hline
\end{tabular}

Mean (SD) values for the 14 age groups are shown for men and women.

$\mathrm{HTQ}=$ Harvard Trauma Questionnaire part IV; PTSD = post traumatic stress disorder.

both HTQ scores and PTSD percentages were identical as the age group of the 41 to 45 -year-olds was found to top both ranking lists.

\section{Discussion \\ PTSD prevalence}

The PTSD prevalence in the total sample of $21.3 \%$ is quite high compared to findings from previous epidemiological studies $[1,6]$. However, the result from the present study is based on a large number of convenience samples that have been shown to result in increased prevalence rates for PTSD compared to epidemiological studies [9]. The PTSD prevalence from the trauma sample in the present study does not show a significantly different PTSD prevalence (21.9\%) from that found in the total sample. Either the difference in PTSD prevalence between epidemiological and convenience samples is not as distinct as previously assumed or more likely, it is due to the overlap between the total sample and the trauma sample. However, the actual prevalence percentages in the samples are not of key interest as the variation due to gender and age on PTSD prevalence is the objective of the present study. Here, the distribution of epidemiological or convenience samples and the large number of the latter are not likely to affect the results to the same extent. It has been suggested that the gender difference in PTSD prevalence is approximately the same for epidemiological samples and convenience samples [9].

\section{Gender differences}

A 2:1 female/male PTSD ratio was found for both the total sample and the trauma sample, which is consistent with the well established finding of an approximately twofold higher PTSD prevalence among women compared to men $[1,6]$. In the total sample the overall PTSD prevalence for men is $13 \%$ and for women it is 27.4\%. However, the female/male PTSD ratio showed some fluctuation between age groups. It also showed variation from the total sample to the trauma sample. The highest female/male PTSD ratio was 3:1 in both samples but the highest ratio was found for a different age group in the total sample ( 21 to 25 years) than in the trauma sample (61 to 65 years). The age group of 71 to 75 years showed the lowest female/male PTSD ratio (1:1.5) in both samples.

Women were found to score higher on the HTQ in both samples. These findings are consistent with previous findings that also pointed out gender differences for the HTQ [15]. The gender difference in the mean scores of the HTQ is highest for the age groups of 21 to 25 years and 51 to 55 years and smallest for the 71 to 75 years. The results from the present study show that men peak in total HTQ scores a decade sooner than women (41 to 45 years and 51 to 55 years, respectively). Additionally, both men and women seem to be more resistant towards PTSD at old age than earlier in their lives, which is consistent with some previous findings [17] but inconsistent with others $[18,19]$.

Some arguments have been made that the increased PTSD prevalence among women is due to a report bias because men tend to under-report and women tend to over-report symptoms of PTSD [27]. Some of the variance has also been suggested to be due to the social expectancy related to the male and female gender role. 
Table 5 Rank of age groups in the total sample by PTSD and HTQ total score

\begin{tabular}{|c|c|c|c|c|c|c|c|c|c|c|c|c|}
\hline \multirow[t]{2}{*}{ Rank } & \multicolumn{4}{|l|}{ Men } & \multicolumn{4}{|l|}{ Women } & \multicolumn{4}{|l|}{ Total } \\
\hline & $\begin{array}{l}\text { Age, } \\
\text { years }\end{array}$ & $\begin{array}{l}\text { PTSD, } \\
\%\end{array}$ & $\begin{array}{l}\text { Age, } \\
\text { years }\end{array}$ & $\begin{array}{l}\text { HTQ total } \\
\text { (SD) }\end{array}$ & $\begin{array}{l}\text { Age, } \\
\text { years }\end{array}$ & $\begin{array}{l}\text { PTSD, } \\
\%\end{array}$ & $\begin{array}{l}\text { Age, } \\
\text { years }\end{array}$ & $\begin{array}{l}\text { HTQ total } \\
\text { (SD) }\end{array}$ & $\begin{array}{l}\text { Age, } \\
\text { years }\end{array}$ & $\begin{array}{l}\text { PTSD, } \\
\%\end{array}$ & $\begin{array}{l}\text { Age, } \\
\text { years }\end{array}$ & $\begin{array}{l}\text { HTQ total } \\
\text { (SD) }\end{array}$ \\
\hline 1 & 41 to 45 & 18.2 & 41 to 45 & $51.71(20.84)$ & 51 to 55 & 42.8 & 51 to 55 & $64.60(17.17)$ & 51 to 55 & 32.5 & 51 to 55 & $58.96(18.50)$ \\
\hline 2 & 46 to 50 & 15.9 & 31 to 35 & $49.86(18.31)$ & 56 to 60 & 39.0 & 56 to 60 & $61.56(17.60)$ & 56 to 60 & 27.8 & 41 to 45 & $57.02(20.18)$ \\
\hline 3 & 51 to 55 & 15.7 & 13 to 15 & 49.85 (17.56) & 21 to 25 & 33.7 & 13 to 15 & 61.15 (20.59) & 41 to 45 & 24.8 & 46 to 50 & $55.85(19.28)$ \\
\hline 4 & 26 to 30 & 14.8 & 51 to 55 & $49.84(16.91)$ & 13 to 15 & 31.1 & 21 to 25 & 60.69 (20.11) & 21 to 25 & 23.2 & 26 to 30 & $55.84(18.24)$ \\
\hline 5 & 36 to 40 & 14.5 & 46 to 50 & 49.64 (19.63) & 41 to 45 & 28.8 & 46 to 50 & $60.45(17.70)$ & 31 to 35 & 22.0 & 13 to 15 & $55.64(19.98)$ \\
\hline 6 & 31 to 35 & 14.4 & 36 to 40 & 49.38 (19.06) & 61 to 65 & 27.5 & 41 to 45 & $60.20(19.10)$ & 26 to 30 & 21.9 & 31 to 35 & $55.53(19.85)$ \\
\hline 7 & 56 to 60 & 13.7 & 26 to 30 & 48.98 (16.50) & 31 to 35 & 26.6 & 26 to 30 & $60.01(18.00)$ & 13 to 15 & 21.5 & 36 to 40 & $55.22(19.09)$ \\
\hline 8 & 76 to 80 & 12.3 & 21 to 25 & $46.60(17.32)$ & 26 to 30 & 26.2 & 31 to 35 & 59.00 (19.98) & 46 to 50 & 21.3 & 56 to 60 & $54.68(18.09)$ \\
\hline 9 & 21 to 25 & 11.7 & 61 to 65 & $46.24(14.27)$ & 46 to 50 & 25.3 & 36 to 40 & $58.87(18.20)$ & 36 to 40 & 20.5 & 21 to 25 & $53.98(20.08)$ \\
\hline 10 & 13 to 15 & 11.3 & 56 to 60 & $46.09(14.76)$ & 36 to 40 & 24.3 & 16 to 20 & $57.11(16.47)$ & 61 to 65 & 19.1 & 16 to 20 & $51.76(16.13)$ \\
\hline 11 & 61 to 65 & 9.7 & 76 to 80 & 45.95 (12.59) & 16 to 20 & 21.1 & 61 to 65 & $54.54(16.95)$ & 76 to 80 & 16.7 & 61 to 65 & $50.61(16.22)$ \\
\hline 12 & 16 to 20 & 7.4 & 16 to 20 & $45.93(13.56)$ & 76 to 80 & 20.6 & 76 to 80 & $51.38(14.37)$ & 16 to 20 & 14.5 & 76 to 80 & $48.80(13.77)$ \\
\hline 13 & 66 to 70 & 7.1 & 71 to 75 & $44.91(11.20)$ & 66 to 70 & 13.7 & 66 to 70 & $48.12(13.07)$ & 66 to 70 & 10.7 & 66 to 70 & $46.03(12.07)$ \\
\hline 14 & 71 to 75 & 6.8 & 66 to 70 & $43.51(10.22)$ & 71 to 75 & 10.3 & 71 to 75 & $46.91(11.25)$ & 71 to 75 & 8.7 & 71 to 75 & $45.97(11.25)$ \\
\hline
\end{tabular}

The ranking of age groups is shown in descending order.

HTQ = Harvard Trauma Questionnaire part IV; PTSD = post traumatic stress disorder.

Where women are expected to be vulnerable, men are expected to be tough and more resilient to trauma [9]. In relation to the lifespan distribution of PTSD it is possible that some of the noticeable features in the prevalence of PTSD are caused by gender roles, life course expectations, or neurobiological developmental changes as well as by variations in trauma exposure.

\section{PTSD prevalence and young age}

Adolescence has been described as being concerned with identity formation and with the task of developing a sense of self-continuity $[28,29]$, which could contribute to the effects seen in the female and male patterns regarding the age groups of 13 to 15 year-olds, and 16 to 20 year-olds. Both the increased starting point for the early adolescents, as well as the following decrease in PTSD vulnerability for late adolescence, may, to some extent, be caused by identity-related issues.

The early 20s are for women characterised by an increased HTQ score. This is consistent with previous trauma and PTSD-related findings [1,7] that demonstrated an increased risk of PTSD among women in their late teens and early 20 s compared to those women at younger age. A long period of adulthood from the 20 s to the 40 s seems to be characterised by a relatively stable level of HTQ scores which indicates that the vulnerability to PTSD is present and somewhat constant for adult women, despite the fact that this period in life is known to hold many life changing moments such as, getting married, starting a family, choosing a career, and so on. Perhaps herein is a great part of the explanation. Frequent changes and individual development happening in tune with the modern female gender role throughout most of the period brings meaning and life satisfaction to each individual woman. However, the vulnerability rises to its peak around the early 50s where the risk of PTSD is significantly high. This deviates from the previous level of HTQ scores and hereby indicates a significant change in the life course caused by neurobiological or other factors.

\section{Midlife crisis}

Fluctuations in the reproductive hormones across menstrual phase and reproductive state in women have been found to influence the sympathetic system reactivity [30]. An increased level of activity in the sympathetic or noradrenergic systems has additionally been found to be present in men and women with PTSD. It is, therefore, plausible that exposure to traumatic stress during different phases of the menstrual or reproductive cycles could influence the vulnerability to PTSD due to different effects at a neurobiological level. Menopausal women have shown increased cardiovascular and epinephrine responses to mental stress compared to premenopausal women [31], and PTSD symptoms have been associated with ambulatory cardiovascular functioning in postmenopausal women [32]. This might provide a neurobiological explanation for the increased HTQ scores found for women at the age of 51 to 55 years in the present study. The age of 51 to 55 years is equivalent to the age of menopause. Changes in reproductive ability, hormonal levels, and sympathetic responses are some of the likely changes that happen along the transition from a premenopausal to a postmenopausal woman. The 
changes are, therefore, not merely neurobiological but also involve potential changes in self-perception, social participation, world beliefs, and adaptation to social gender roles. These changes might also add to an increased stress level or a greater vulnerability to PTSD.

For men a different pattern is seen in adulthood. The male pattern is characterised by a steady almost linear increase in HTQ scores, which begins in the late teens or early 20 s and lasts to the early 40 s, where the HTQ scores for men peaks. It is conceivable that the gradual rise in the risk of PTSD happens concordantly with a gradual change in the male gender role from being free and able to do as they please to being tied up with work and family responsibilities, resulting in a life with less autonomy and potentially more stress. The phenomena of male midlife crisis might, to some extent, influence the results in HTQ scores found in men.

\section{PTSD prevalence in old age}

A distinct decrease in HTQ scores is seen for women after the 50s and the lowest level is found for women in their late 60s or early 70s. For men a decrease in HTQ scores is also seen towards old age. After the 40s men show a gradual fall in the risk of PTSD. The lowest potential risk of PTSD is thus found for men in their late 60s. Old age has been considered to deal with the acceptance of earlier experiences in life and the fact that death is more imminent than earlier [33]. According to Erikson [34] old age is concerned with the psychosocial crisis of ego integrity versus despair. If the crisis is resolved favourably, ego integrity, wisdom, and life satisfaction is reached [33,34]. This could in fact be part of the reason for the decreased risk of PTSD seen in the $50 \mathrm{~s}$ and $60 \mathrm{~s}$ for men and in the late $50 \mathrm{~s}, 60 \mathrm{~s}$, and early 70 s for women. Some suggestions have additionally been made that a decline in self-occupation, an increase in time spent in quiet reflection, and a decreased interest in superfluous social interactions also are characteristic of old age [35]. Satisfaction with the life led, wisdom in retrospect, and the acceptance of a forthcoming death without fear may very likely affect coping strategies and resilience to PTSD in a positive way. However, this is challenged by the results for both men and women in the present study. Thus, the risk of PTSD shows a small linear increase from the late 60 s to the late 70s for men and from the mid to late 70s for women. It has been suggested that reaching the age of 80 or more involves special challenges and perhaps a new stage in psychosocial development [33,34]. If this is the case the vulnerability to PTSD might also be different and involve special issues at such an old age. The effect might, to a limited degree, be detectable in the results for the 70 or 80 -year-olds in the present study and thus explain the final rise seen in the HTQ scores.

\section{Comparison with previous studies}

Kessler et al. [1] found that the age group of 45 to 54year-olds showed the highest risk of PTSD among men. Among women they found it to be between the age of 25 and 34 years. Creamer and Parslow [14] found the highest risk of PTSD to be present between the age of 18 and 24 years for both men and women. When converting our results into comparable 10-year-span age groups the highest risk of PTSD was found between the age of 45 and 54 years among men, and 55 and 64 years among women. The results for men are congruent with the findings by Kessler et al. The results for women, however, show a 30-year difference in PTSD peaks between the two studies. However, the age group of 55 to 64-year-olds was not included in the Kessler et al. study. The inconsistency with the findings of Creamer and Parslow could be due to methodological or cultural differences.

The findings from the present study describe the effect of gender and age on PTSD prevalence in a Nordic country culture context. The results for effect of age on PTSD prevalence resemble the results found by Norris et al. [13] in relation to an American culture context. The total picture of PTSD prevalence (based on HTQ mean score) associated with age shows that the prevalence of PTSD follows a curvilinear picture where middle-aged participants show a higher degree of PTSD than young participants, who again show a higher level of PTSD than older people. The results, thereby, are somewhat similar to the ones found in the US by Norris et al. and might reflect how PTSD appears in Western cultures. In contrast, Maercker et al. [18] found a higher prevalence of PTSD among participants above the age of 60 years in Germany. This might show that cultural comparison of PTSD prevalence or other psychological measures can be delicate due to, for example, historical, economical, or political reasons.

\section{Age group ranking}

Both the HTQ mean scores as well as the categorical PTSD scores can be seen as a way to estimate the potential risk of PTSD or the vulnerability to PTSD. The dimensional and categorical results of PTSD were both ranked by age groups in order to find the estimated distribution of PTSD prevalence according to age. The results show differences in the rank of age groups due to a dimensionally (HTQ) or a categorically (PTSD\%) estimated PTSD prevalence. The rankings of age groups can be seen in Table 5 . The highest rank for women by both the PTSD percentages and the HTQ scores is found for women at the age of 51 to 55 years. For men the highest rank for both HTQ scores and PTSD percentages are identical as the age group of the 41 to 45 -year-olds is found to top both ranking lists for 
men. The second and third most PTSD vulnerable age groups according to the HTQ are the 31 to 35 years sample and the 13 to 15 years sample among men and the 56 to 60 years sample and the 13 to 15 years sample among women. For the categorical PTSD prevalence the second and third rank are found for the 46 to 50 years sample and the 51 to 55 years sample among men and the 56 to 60 years and the 21 to 25 years samples among women. Thus, the two types of measurement primarily show differences in the ranking of age groups but some congruent results are found. Recent articles indicate that the future choice of measurement in the DSM will favour the dimensional proportions [36,37]. As indicated by the results from the present study differences are seen between the two types of measurement. Which is preferable to the other is not settled by the present study, but the HTQ score does withhold more information. Thus, the results based on the dimensional approach might be more differentiated. This might add some consideration to the ongoing discussion of the preference of dimensional models rather than categorical measures in the research agenda for the DSM-V [38].

\section{Limitations of the study}

In this study, 25 different studies were included to test the hypothesis that men and women show a difference in age distribution of PTSD prevalence. Possible limitations due to a lack of representativeness in the samples, undetected cohort effects, and biases due to method failure are likely to have influenced the results. However, a great strength of the study is the size of the population by which each age group has reached a certain representative size. All the data has been analysed by retrospective analysis and no contact has been made with any participants in the process of the present study. Possible reporting biases could, therefore, have gone undetected or have been deleted due to ambiguity. A large part (76\%) of the total sample consisted of convenience samples. This of course must be viewed as a potential limitation of the study and must be taken into account when interpreting the results of PTSD prevalence.

Another limitation of the study concerns cultural considerations. The present study is based on data gathered in the Nordic countries of Denmark, Iceland, and The Faroe Islands. The results, therefore, must be taken with some consideration when comparing to other countries or areas outside the Nordic region. Norris et al. [13] clearly showed that cultural differences are found in the PTSD prevalence rates. Therefore, it is likely that cultural considerations account for some of the variance seen in the present study. It is desirable that the combined effect of gender and age on PTSD is studied in other parts of the world in order to see if the present study has created a precedent for the combined effect of gender and age on PTSD or for the lifespan distribution of PTSD.

\section{Future research}

To conclude on the matter of gender differences in the lifespan distribution of PTSD it would be beneficial to compare the age distribution of PTSD prevalence with the age distribution of trauma exposure in order to find potential discrepancies and in order to clarify the true extent of the vulnerability or risk of PTSD. If controlling for trauma exposure does not indicate that the combined gender and age effect on PTSD is due to increased trauma exposure at certain periods in the male or female life course then the results from the present study demand further research. Thus, the goal of future research would be to verify the presented findings as well as to find possible explanations for these findings. Future research should focus on the construction of usable and representative age groups with inclusion of not only young and adults but also older people in order to describe the entire lifespan of PTSD distribution. The inclusion of participants beyond the age of 80 would touch on something new and concurrently bring diversity into the range of the population examined. Future research should also include an examination of the association of different trauma types in order to find possible exposure biases or other possible effects seen from specific trauma types.

The combined effect of gender and age on PTSD has previously been given little attention in the PTSD literature. However, the results from the present study indicate that it makes sense to consider the combined effect of gender and age on PTSD as it outlines how risk of PTSD or PTSD vulnerability can be seen in a lifetime perspective. The lifespan distribution of PTSD shows that men are most vulnerable to PTSD a decade sooner than women. This difference is of particular interest and needs to be investigated further in future research in order to develop more thorough explanations for the effect.

\section{Summary}

The hypotheses made for the present study are verified by the results found. The first hypothesis, that the lifespan distribution of PTSD will be different for men and women, is supported by the results. Women and men are found to show different lifespan distributions of PTSD. However, some similarities are seen in the fluctuations of HTQ score during the lifespan. Thus, some of the rises and falls in HTQ scores follow the same age pattern for men and women and are only different in terms of an elevated level of scores among women and in the gender-related ranking of age groups. In contrast, 
the most evident difference consists of the rise in HTQ scores around the early 50s for women, which is simultaneous with a fall in HTQ scores for men. The main differences thus consist of an elevated level of HTQ scores or PTSD prevalence for women compared to men, and a peak in HTQ scores or PTSD prevalence found at different points during the lifespan for men and women, respectively. This hints that verification is also found for the second hypothesis, that women at all ages will show a higher prevalence of PTSD than men. Support for this second hypothesis is found both in terms of dimensionally (HTQ score) and categorically (qualification for PTSD criteria) measured PTSD. Confirmation is not found in the results for the last hypothesis, that men will show their highest level of PTSD prevalence later in life compared to women. The male participants from the present study showed their highest level of PTSD prevalence about a decade sooner in their lifespan compared to the female participants.

\section{Conclusions}

The findings from the present study differ from previous findings regarding the combined effect of gender and age on PTSD prevalence. The results for men show some consistency with previous findings, whereas, the results for women do not. The results show that men are most vulnerable to PTSD at the age of 41 to 45 years, whereas, women are most vulnerable to PTSD at the age of 51 to 55 years. Thus, men and women peak in the risk of PTSD a decade apart from each other during their respective lifespan. The female/male ratio of PTSD prevalence is found to vary between the different age groups. However, at all ages from 13 to 80 years women show a higher level of PTSD prevalence than men.

\section{Author details}

${ }^{1}$ Department of Psychology and Multidisciplinary Chronic Pain Clinic, Odense University Hospital, Odense, Denmark. ${ }^{2}$ National Centre for Psychotraumatology, University of Southern Denmark, Odense, Denmark.

\section{Authors' contributions}

AE conceived the study and participated in the design of the study. DND prepared the data file, performed the statistical analysis, and drafted the manuscript. Both authors read and approved the final manuscript.

\section{Competing interests}

The authors declare that they have no competing interests.

Received: 10 December 2009 Accepted: 21 July 2010

Published: 21 July 2010

\section{References}

1. Kessler RC, Sonnega A, Bromet E, Hughes M, Nelson CB: Posttraumatic stress disorder in the National Comorbidity Survey. Arch Gen Psychiatry 1999, 52:1048-1060.

2. Riley JC: Rising Life Expectancy: A Global History New York, USA: Cambridge University Press 2001.

3. The World Factbook (2009). [https://www.cia.gov/library/publications/theworld-factbook].
4. Bloom F, Nelson CA, Lazerson A: Brain, Mind and Behavior New York, USA: Worth Publishers 2001.

5. Wang J, Korczykowski M, Rao H, Fan Y, Pluta J, Gur RC, McEwen BS, Detre JA: Gender difference in neural response to psychological stress. Soc Cogn Affect Neurosci 2007, 2:227-239.

6. Breslau N, Kessler RC, Chilcoat HD, Schultz LR, Davis GC, Andreski P: Trauma and posttraumatic stress disorder in the community: The 1996 Detroit Area Survey of Trauma. Arch Gen Psychiatry 1998, 55:626-632.

7. Perkonigg A, Kessler RC, Storz S, Wittchen HU: Traumatic events and posttraumatic stress disorder in the community: prevalence, risk factors and comorbidity. Acta Psychiatr Scand 2000, 101:46-59.

8. Stein MB, Walker JR, Hazen AL, Forde DR: Full and partial posttraumatic stress disorder: findings from a community survey. Am J Psychiatry 1997, 154:1114-1119.

9. Tolin DF, Foa EB: Sex differences in trauma and posttraumatic stress disorder: a quantitative review of 25 years of research. Psychol Bull 2006, 132:959-992.

10. Cortina LM, Kubiak SP: Gender and posttraumatic stress: sexual violence as an explanation for women's increased risk. J Abnorm Psychol 2006, 115:753-759.

11. Ditlevsen DN: The Trauma Type Related Variance of Gender Differences in PTSD Prevalence: A Meta-analysis of 15 Danish and 3 Icelandic Convenience Samples Aarhus, Denmark: Institute of Psychology 2009.

12. Thomson MP, Norris FH, Hanacek B: Age differences in the psychological consequences of hurricane Hugo. Psychol Aging 1993, 8:606-616.

13. Norris FH, Kaniasty K, Conrad ML, Inman GL, Murphy AD: Placing age differences in cultural context: a comparison of the effects of age on PTSD after disasters in the United States, Mexico, and Poland. J Clin Geropsychol 2002, 8:153-173.

14. Creamer M, Parslow R: Trauma exposure and posttraumatic stress disorder in the elderly: a community prevalence study. Am J Geriatr Psychiatry 2008, 16:853-856.

15. Elklit $\mathrm{A}$, Petersen $\mathrm{T}$ : Exposure to traumatic events among adolescents in four nations. Torture 2008, 18:2-11.

16. Elklit A, Simonsen E: MCMI-III En introduktion til Millon Clinical Multiaxial Inventory Copenhagen, Denmark: Dansk Psykologisk Forlag 2005, [in Danish]

17. Frueh BC, Grubaugh AL, Acierno R, Elbai JD, Cain G, Magruder KM: Age differences in posttraumatic stress disorder, psychiatric disorders, and healthcare service use among veterans in veterans primary care clinics. Am J Geriatr Psychiatry 2007, 15:660-672.

18. Maercker A, Forstmeier S, Wagner B, Glaesmer H, Brähler E: Posttraumatische Belastungsstörungen in Deutschland: Ergebnisse einer gesamtdeutschen epidemiologischen Untersuchung [in German]. Der Nervenarzt 2008, 79:577-586.

19. Spitzer C, Barnow S, Völzke H, John U, Freyberger HJ, Grabe HJ: Trauma and posttraumatic stress disorder in the elderly: findings from a German community study. J Clin Psychiatry 2008, 69:693-700.

20. Elklit A, O'Connor M: Post-traumatic stress disorder in a Danish population of elderly bereaved. Scand I Psychol 2005, 46:439-445.

21. Christiansen DM, Elklit A: Risk-factors predict post-traumatic stress disorder differently in men and women. Ann Gen Psychiatry 2008, 7:24.

22. Bromet E, Sonnega A, Kessler RC: Risk factors for DSM-III-R posttraumatic stress disorder: findings from the national comorbidity survey. Am J Epidemiol 1998, 147:353-361.

23. Hapke U, Schumann A, Rumpf HJ, John U, Meyer C: Post-traumatic stress disorder: the role of trauma, pre-existing psychiatric disorders, and gender. Eur Arch Psychiatry Clin Neurosci 2006, 256:299-306.

24. Mollica RF, Caspi-Yavin Y, Bollini P, Truong T, Tor S, Lavelle J: The Harvard Trauma Questionnaire: validating a cross-cultural instrument for measuring torture, trauma and posttraumatic stress disorder in Indochinese refugees. J Nerv Ment Dis 1992, 180:111-116.

25. American Psychiatric Association: Diagnostic and Statistical Manual of Mental Disorders Washington, DC: APA, 41994.

26. Bach ME: En empirisk belysning og analyse af "emotional numbing" som eventuel selvstændig factor i PTSD. [An empirical description and analysis of "emotional numbing", as a potential independent factor in PTSD]. Psykologisk Studieskriftserie 2003, 6:1-132.

27. Saxe G, Wolfe J: Gender and posttraumatic stress disorder. Posttraumatic Stress Disorder: A Comprehensive Text Boston, MA, USA: Allyn and BaconSaigh PA, Bremner JD 1999, 160-179. 
28. Dunkel CS, Sefcek JA: Eriksonian lifespan theory and life history theory: an integration using the example of identity formation. Rev Gen Psychol 2009, 13:13-23.

29. Erikson EH: Youth: fidelity and diversity. Daedalus 1988, 117:1-24.

30. Rasmusson AM, Friedman MJ: Gender issues in the neurobiology of PTSD. Gender and PTSD New York, USA: Guilford Presskimerling R, Ouimette P, Wolfe J 2002.

31. Saab PG, Matthews KA, Stoney CM, McDonald RH: Premenopausal and postmenopausal women differ in their cardiovascular and neuroendocrine responses to behavioral stressors. Psychophysiology 1989, 26:270-280.

32. Newton TL, Parker BC, Ho IK: Ambulatory cardiovascular functioning in healthy postmenopausal women with victimization histories. Biol Psychol 2005, 70:121-130.

33. Brown C, Lowis MJ: Psychosocial development in the elderly: an investigation into Erikson's ninth stage. J Aging Stud 2003, 17:415-426.

34. Erikson EH: The life cycle completed: A review - Extended version New York, USA: W. W. Norton \& Company 1998

35. Tornstam $L$ : Gerotranscendence from young old age to old age. [http:// www.soc.uu.se/research/gerontology/pdf/gtransoldold.pdf].

36. Clark LA: Assessment and diagnosis of personality disorder: perennial issues and an emerging reconceptualization. Ann Rev Psychol 2002, 58:227-257.

37. Rounsaville BJ, Alarcon RD, Andrews G, Jackson JS, Kendell RE, Kendler K: Basic nomenclature issues for DSM-V. A Research Agenda for DSM-V Washington, DC: American Psychiatric AssociationKupfer DJ, First MB, Regier DE 2002, 1-29

38. Rossi G, Elklit A, Simonsen E: Empirical evidence for a four factor framework of personality disorder organization: multigroup confirmatory factor analysis of the Millon Clinical Multiaxial Inventory - III personality disorder scales across Belgian and Danish data samples. J Personal Disord 2010, 24:128-150.

doi:10.1186/1744-859X-9-32

Cite this article as: Ditlevsen and Elklit: The combined effect of gender and age on post traumatic stress disorder: do men and women show differences in the lifespan distribution of the disorder? Annals of General Psychiatry 2010 9:32.

\section{Submit your next manuscript to BioMed Central and take full advantage of:}

- Convenient online submission

- Thorough peer review

- No space constraints or color figure charges

- Immediate publication on acceptance

- Inclusion in PubMed, CAS, Scopus and Google Scholar

- Research which is freely available for redistribution

Submit your manuscript at www.biomedcentral.com/submit 